\title{
Chondroma of the falx cerebri
}

\section{CONDROMA DA FOICE CEREBRAL}

Pedro Tadao Hamamoto Filho ${ }^{1}$, Antonio Tadeu de Souza Faleiros ${ }^{2}$, Michell Frank Alves de Oliveira ${ }^{3}$, Marco Antônio Zanini ${ }^{4}$,

Maria Aparecida Marchesan Rodrigues ${ }^{5}$

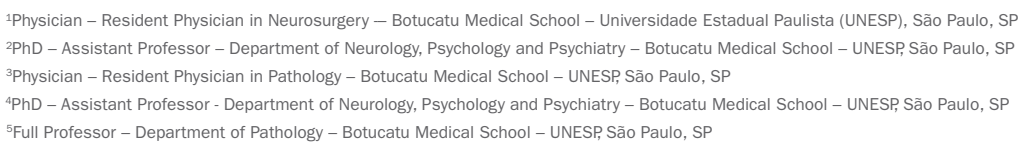

Study conducted at Botucatu Medical School - UNESP

\section{INTRODUCTION}

Chondromas account for $0.2-0.3 \%$ of all intracranial tumors. ${ }^{1,2}$ Most are found at the skull base near to the spheno-ethmoidal and spheno-occipital synchondrosis. ${ }^{3}$ It is accepted that cartilaginous precursors of the skull base may predispose to the development of this tumor. On the other hand, chondromas are rarely found on the skull convexity, which develops through intramembranous ossification. ${ }^{4}$

Clinical presentation is unspecific and depends on tumor location and on the presence or absence of intracranial hypertension. ${ }^{5}$ These tumors may be misdiagnosed as meningiomas on preoperative evaluations. Complete surgical resection is the best therapeutic choice.

\section{Case report}

A 57-year-old man presented to our hospital with a 20year history of essential tremor. His previous medical history was negative for other diseases. No other abnormality was seen on neurological examination.

Magnetic resonance imaging (MRI) showed a homogeneous mass attached to the falx cerebri (Figure 1). It had an isointense signal on both $\mathrm{T} 1$ and $\mathrm{T} 2$ weighted images. Minimum enhancement was observed near the superior border of the tumor.

The patient was treated with a parasagittal craniotomy. Total gross resection was obtained with an unremarkable postoperative course.

Pathological examination showed a nodular tumor with well-defined margins, measuring $7.5 \times 4.2 \times 2.5 \mathrm{~cm}$.
On the histopathologic analysis, the lesion consisted of lobules of hypocellular mature hyaline cartilage with abundant blue-grey chondroid matrix punctuated by in-
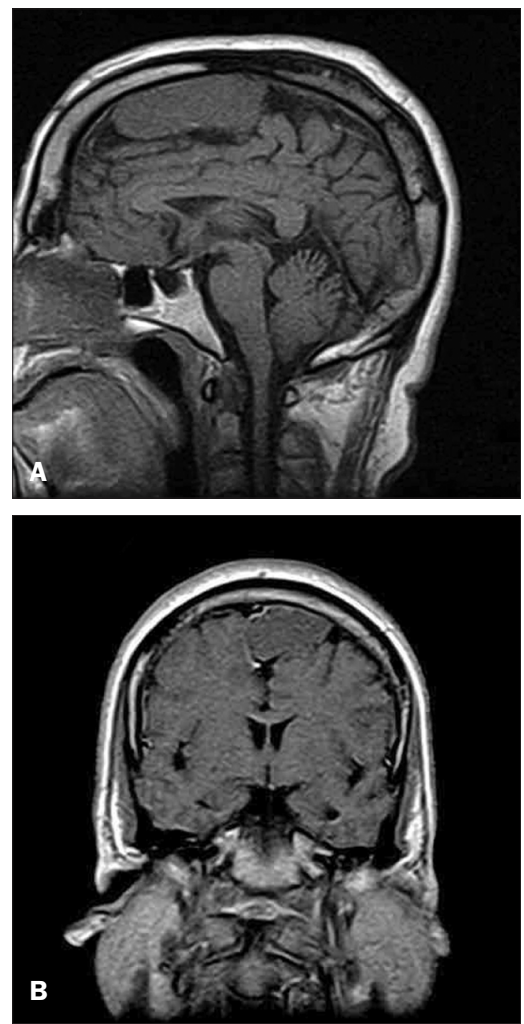

FIGURE 1 T1-weighted MRI shows an isosignal tumor from the falx cerebri to the left. A: sagittal view; B: coronal view. 
dividual chondrocytes in small lacunar spaces (Figure 2). Chondrocytes within the lacunae presented bland cytological features and a complete absence of mitotic figures, thus featuring a chondroma.

A 1-year post-operative MRI showed no residual tumor or recurrence, but cure of the essential tremor was not achieved.

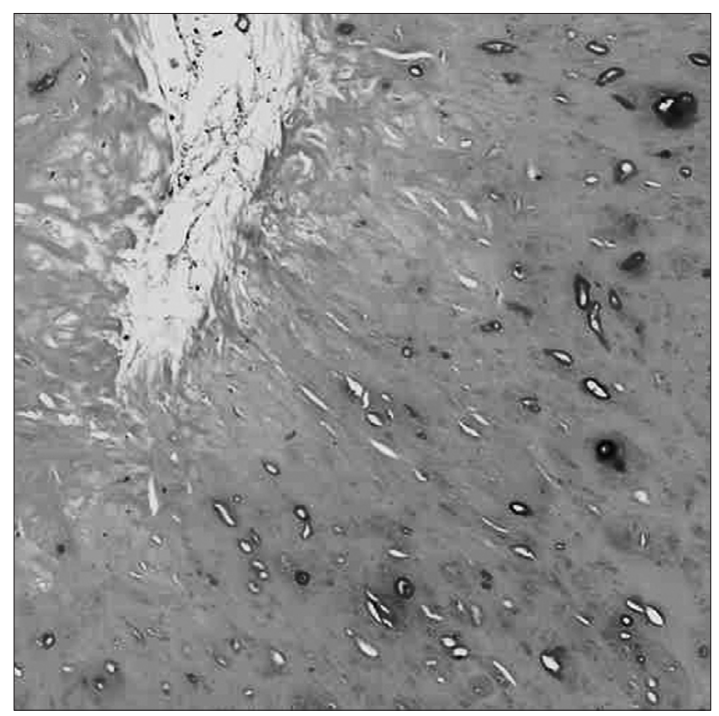

FIGURE 2 Microscopic view of chondroma: mature chondrocytes without atypia within a dense chondroid matrix (Hematoxylin and Eosin 400x).

\section{Discussion}

Intracranial chondromas are most common on the skull base. This may be related to the cartilaginous ossification of base of the cranium. It is quite rare to find chondromas on the skull convexity, where ossification is membranous. Literature has pointed out some theories on the origin of chondromas on the skull convexity and falx cerebri, such as: metaplasia of meningeal fibroblasts and perivascular meningeal tissue, heterotopic embryonic cartilaginous rests, and displacement or migration of cartilaginous cells due to trauma of inflammatory process. ${ }^{1,4}$ Intracranial chondromas may also be associated with diseases of cartilage tissue, like multiple enchondromatosis (Ollier disease) and Maffuci syndrome. ${ }^{6}$

Clinical presentation is variable and includes focal deficits, epilepsy, headache and vomiting. Headache and epilepsy are the most common symptoms. ${ }^{7}$ The peak of incidence is the third decade of life, but it may range from 15 months to 60 years. ${ }^{4}$

Magnetic resonance imaging (MRI) shows tumors with well-defined shape, irregular contour and precise limits. Tumors present an iso- to hyposignal at T1-weighted images. Contrast enhancement is poor. Computed tomography may show foci of calcification and adjacent bony erosion or hyperostosis. ${ }^{4,6}$

Some authors have called attention to the differential diagnosis with meningiomas. So it would be helpful to perform an angiogram to differentiate them, since chondromas are avascular masses while meningiomas have an intense tumor blush. ${ }^{8}$ However, we believe that the pattern of low enhancement of chondromas is sufficient to justify preoperative suspicion.

Treatment of choice is surgery with total gross resection, which allows for low rates of recurrence and a good prognosis. ${ }^{2}$ This tumor is not radiosensitive and radiation may predispose to malignant degeneration. ${ }^{1}$

\section{References}

1. Erdogan S, Zorludemir S, Erman T, Akgul E, Ergin M, Ildan F, Bagdatoglu $\mathrm{H}$. Chondromas of the falx cerebri and dural convexity: report of two cases and review of the literature. J Neurooncol 2006; 80:21-25.

2. Patel A, Munthali L, Bodi I. Giant cystic intracranial chondroma of the falx with review of literature. Neuropathology 2009; 29:315-317.

3. Sarwar M, Swischuk LE, Schechter MM. Intracranial chondromas. Am J Roentgenol 1976; 127:973-977.

4. Fountas KN, Stamatiou S, Barbanis S, Kourtopoulos H. Intracranial falx chondroma: literature review and a case report. Clin Neurol Neurosurg 2008; $110: 8-13$

5. De Coene B, Gilliard C, Grandin C, Nisolle JF, Trigaux JP, Lahdou JB. Unusual location of an intracranial chondroma. Am J Neurorradiol 1997; 18:573-575.

6. Çolpan E, Attar A, Erekul S, Arasil E. Convexity dural chondroma: a case report and review of the literature. J Clin Neurosci 2003; 10(1):106-108.

7. Miura FH, Aguiar PHP, Michailowsky C, Stávale MA, Navarro HT, Martinez JAG, Rotta M. Falx osteochondroma: case report and review of the literature. Arq Neuropsiquiatr 1997;55:618-624.

8. Kumari N, Sahu RN, Krishani N. Meningeal chondroma in a young female. Indian J Pathol Microbiol 2010;53:117-118. 